\title{
Select Crowd Review: A New, Innovative Review Process for the International Journal of Sports Medicine
}

\author{
Bibliography \\ DOI http://dx.doi.org/10.1055/ a-1131-1868 \\ Published online: 2020 \\ Int J Sports Med 2020; 41: 207 \\ (c) Georg Thieme Verlag KG Stuttgart · New York \\ ISSN 0172-4622
}

The quality of scientific articles is traditionally assured by the peer-review process. The IJSM uses double-blind peer review, in which the authors' and reviewers' identities are kept anonymous. Peer review is a core element of scientific publishing and one of the most important issues in today's research climate is to deliver a rapid publishing process without compromising quality or integrity.

However, the whole peer-review process until a final decision is made is often not timely. Each year the number of scientific papers submitted continues to grow, which puts increasing pressure on the system. For the single reviewer this is resulting in an overload of requests to prepare further reviews. Moreover, medicine and natural sciences are subject to increasingly narrow specialization. This limits the number of potential reviewers who are qualified and willing to evaluate a manuscript in its entirety. This situation invites us to look for alternative systems, models and solutions for the quality assurance and sustained efficiency of scientific publications.

\section{Select Crowd Reviewing: A Form of Collective Peer Review}

The Select Crowd Review process uses the mechanisms of social media communication. It is an interactive and safe way to to make the review process much faster than classical peer review. Select Crowd Review was first introduced for Thieme's chemical synthesis journal SYNLETT in 2017 and allows editors an evaluation of a manuscript within a comparatively short period of time.

\section{How it Works}

A selection of several experts, who are exclusive members of the crowd, receive a link to the manuscript and can comment on it anonymously via a secure web-interface. Select Crowd Review meets the requirements of IJSM's double-blind peer review: only the Crowd-Review Editor knows who the reviewers are, while monitoring the process. The author's identity is not revealed to the crowd members, and vice versa.

Each reviewer decides if he or she has time and expertise to comment on the respective article. Participating reviewers see each other's (anonymous) comments and can discuss the research fea- tured in the paper to improve the manuscript further. They can respond, interact, and enhance it in parallel.

The Crowd-Review Editor decides on the termination of the review period. When the review period ends, the manuscript is taken off the platform. In the next step, the Crowd-Review Editor evaluates the comments of the reviewers, decides about accepting (with or without revision) or rejecting the article, and sends the feedback of the crowd to the author for consideration and implementation.

\section{What it Offers}

Experience with Select Crowd Review has shown that the innovative process delivers substantive feedback to the authors, with the same or higher quality than classical peer review does, frequently within a few days. This allows editors to decide about the acceptance of a manuscript much faster and therefore shortens the time from submission to publication.

\section{Submit your Paper and try Select Crowd Review now!}

The IJSM is offering Select Crowd Review to authors on a voluntary basis:

1. By submitting your manuscript to the IJSM and selecting "Crowd Review" as your preference, you can experience and discover the process for yourself.

2. As in the past, you can also choose exclusively classic peer review.

3. You can also choose both classic peer review and Select Crowd Review in parallel to compare the results.

We are delighted that Dr. Madeleine Davies, Research Associate in Severe Sports Injury, Department of Health, University of Bath, UK, has accepted our invitation to become the Crowd-Review Editor for the new review process. We would like to thank everyone involved in this ambitious project and look forward with eager anticipation how this reviewing format will grow and develop.

We are looking forward to your manuscripts for the IJSM!

The editors and the publisher 